\title{
Estimation of Total Daily Energy Expenditure and Its Components by Monitoring the Heart Rate of Japanese Endurance Athletes
}

\author{
Keiko Motonaga ${ }^{1,2}$, Shigeko YoshidA ${ }^{3}$, Fumiko YAmagami ${ }^{4}$, \\ Tadasu KAWANO ${ }^{4}$ and Eiji TAKEDA ${ }^{2}$ \\ ${ }^{1}$ Department of Care Work, Faculty of Social Welfare, Kinki Welfare University, \\ 1966-5, Takaoka Fukusaki, Kanzaki, Hyogo 679-2217, Japan \\ ${ }^{2}$ Department of Clinical Nutrition, Institute of Health Biosciences, University of Tokushima Graduate School, \\ 3-18-15, Kuramoto, Tokushima 770-8503, Japan \\ ${ }^{3}$ Department of Health and Sports Science, Faculty of Life Science, Kurashiki University of Science and the \\ Arts, 2640, Nishinoura, Tsurajima, Kurashiki, Okayama 712-8505, Japan \\ ${ }^{4}$ Otsuka Pharmaceutical Factory, Inc. Track and Field Team, \\ 115 Tateiwa, Muya-cho, Naruto, Tokushima 772-8601, Japan \\ (Received March 15, 2006)
}

\begin{abstract}
Summary The estimation of total daily energy expenditure (TEE) or the energy needs of athletes is important for maintaining a proper energy balance during training. This study was conducted to measure the TEE of Japanese middle- and long-distance runners using a heart-rate monitoring method (the HR method), and to ascertain the impact of three key energy expenditure (EE) components occurring within the day; sleep, exercise (training) and inactivity (other daily habitual activities). Additionally, energy balance was evaluated by comparing TEE with energy intake (EI). The mean TEE of six male athletes aged 19-21 y was $4,514 \pm 739 \mathrm{kcal} / \mathrm{d}$ and their mean EI was $3,784 \pm 91 \mathrm{kcal} / \mathrm{d}$ during the training period of $11 \mathrm{~d}$. This negative energy balance led to a significant decline in body weight $(p<0.01)$, indicating that proper care should be taken to balance energy during training. The mean daily EEs during sleep, inactivity, and exercise were $536 \pm 46$ (12.0\% of TEE), $1,722 \pm 145(38.7 \%)$, and $2,255 \pm 658(49.3 \%) \mathrm{kcal} / \mathrm{d}$, respectively. There was a significant correlation between TEE and exercise EE $(p<0.01)$ in the athletes. The TEE of the endurance athletes was higher than expected and significantly affected by exercise EE, indicating that the TEE of athletes, in general, must be carefully evaluated before incorporating nutritional support for them.
\end{abstract}

Key Words energy expenditure, HR method, endurance athletes, energy intake, sports nutrition

Japanese athletes have recently taken active part in various competitions. Higher energy expenditure (EE) is required for athletic training and competition (1). To keep a good energy balance for achieving and maintaining adequate body weight (BW), body composition, and glycogen storage, athletes have to consume sufficient food to match their total daily energy expenditure (TEE) or energy needs (2). In this respect, both the quantity and quality of exercise training and diet are considered important for the athletes. The daily dietary needs, combined with the enhanced EE due to athletic activity, require proper energy management and balanced nutrition. For example, managing the EE during the daytime (i.e., in between training periods) is critical for maintaining balanced health. This calls for a study of not only TEE, but also the different components that make up the TEE.

In Japan, there have been several studies on the TEE of athletes in major sports like soccer and baseball (35). Some recent studies have compared the TEE in ath-

E-mail: motonaga@sw.kinwu.ac.jp letes participating in endurance sports versus resistance sports or untrained subjects $(6-8)$. Others have compared TEE with energy intake (EI) in athletes, demonstrating how important both the quality and quantity of their meals are for maintaining a better physical condition $(6,9-11)$. Sugiura et al. surveyed the mean daily intake of energy and nutrients of elite Japanese track-and-field athletes using a 3-d food record (12). However, they compared the nutritional intake versus the Japanese Recommended Dietary allowance (JRDA) without measuring the athletes' actual EE. The measurement of energy needs is indispensable for determining the nutrition requirements of the athletes. However, there have been few reports where both the TEE and EI of the athletes have been examined. Therefore, detailed investigations are necessary to create better nutritional support for athletes.

The doubly labeled water method (DLW method), which provides the most accurate estimate of TEE, has been regarded as the "gold standard" for the measurement of TEE under free-living conditions (13). However, the method is not always suitable for detailed measure- 
ment of EE in athletes because (a) it is costly, (b) it requires much time, at least $7 \mathrm{~d}$, to finalize data, and (c) it is difficult to accurately estimate the EEs of activities at shorter time intervals. Most other simpler methods of activity measurement such as pedometers, accelerometers, calorie counters, or heart rate (HR) monitors have the disadvantage of low accuracy.

Among the simpler methods mentioned above, however, the HR monitor is a convenient tool and provides a reasonable estimate of EE during specific exercises (14). HR is linearly related to EE in dynamic activities involving large muscle groups $(9,14,15)$, and is frequently used as an indicator of exercise intensity as expressed by percentage of $\mathrm{HR}_{\max }$ or $\mathrm{HR}$ reserve (4). The estimation of TEE using the HR monitoring method (HR method) is based on the principle that there is a reliable correlation between HR and oxygen consumption $(16,17)$. Livingstone et al. have reported that the result of TEE measured using the HR method is similar to TEE measured using the DLW method (18). The HR method is relatively cheap, easy and simple, as compared to the DLW method, for monitoring EEs in various situations (6, 16-20). Many athletes routinely use the HR monitor as a tool for their own health management and training (16). For these reasons, we employed the HR method to estimate the TEE of athletes in this study.

The types of HR method used so far by various researchers can be classified into three categories based primarily on the way regression equations between HR and EE are set up: (a) FLEX-HR method (15, 17, 2123), (b) log-linear method (13, 24-27), and (c) logistic method $(19,20,28)$. Ekelund et al. concluded that the estimates of TEE using the FLEX-HR method are close enough to those obtained using the DLW method in young speed skaters (1). However, Kashiwazaki com- pared TEE measured using all three methods with the DLW method and concluded that the log-linear method gave the best estimate of TEE (13). Based on these observations, and after close examination of our own data, the HR log-linear method was adopted to estimate TEE and other EEs in this study on endurance runners.

One of the objectives of this study is to estimate, using the HR method, TEE in Japanese athletes under training and during three daily components of sleep, exercise (training) and inactivity (other daily habitual activities), and to find out how much each component contributes to TEE. To our knowledge, there are very few reports where TEE measurements of athletes have been made covering a range of daily activities spanning an entire day. Another objective is to examine their energy balance by comparing TEE with EI. It is expected that the outcome of this study will contribute to better energy management during training and the daily life activities of athletes.

\section{METHODS}

Subjects. Six Japanese male sub-elite runners aged 19-21 y participated in this study. They had no history of any metabolic disorders. The purpose of the study was fully explained to all the subjects, and their informed consent was obtained. The study protocol conformed to the ethical guidelines of the 1975 Declaration of Helsinki, as reflected in prior approval by each institution's review board for human research. All the subjects were well trained competitive middle- or longdistance runners, and belonged to an athletic team of a private company. The physical characteristics of these subjects are shown in Table 1. This study was conducted over 11 consecutive days, during which the subjects were engaged in training (Fig. 1). The training

Table 1. Physical characteristics of the subjects.

\begin{tabular}{lrrrrrrr}
\hline \multicolumn{1}{c}{ Subject } & \multicolumn{1}{c}{ A } & \multicolumn{1}{c}{ B } & \multicolumn{1}{c}{ C } & D & E & F & Mean \pm SD \\
\hline Height $(\mathrm{cm})$ & 166.0 & 180.0 & 173.0 & 174.0 & 164.0 & 173.0 & $171.7 \pm 5.8$ \\
Weight $(\mathrm{kg})$ & 55.1 & 61.3 & 58.8 & 59.4 & 53.8 & 54.7 & $57.2 \pm 3.0$ \\
Percent fat mass (\%) & 12.4 & 9.4 & 11.6 & 12.8 & 15.9 & 12.0 & $12.4 \pm 2.1$ \\
Percent fat free mass (\%) & 87.6 & 90.6 & 88.4 & 87.2 & 84.1 & 88.0 & $87.7 \pm 2.1$ \\
BMI $\left(\mathrm{kg} / \mathrm{m}^{2}\right.$ ) & 20.0 & 18.9 & 19.6 & 19.6 & 20.0 & 18.3 & $19.4 \pm 10.7$ \\
11-d weight change $(\mathrm{kg})$ & -2.0 & -1.5 & -1.5 & -0.3 & -0.2 & 0.6 & $-0.8 \pm 1.0^{\mathrm{a}}$ \\
Running distance $(\mathrm{km} / \mathrm{mo})$ & 679.3 & 710.0 & 683.9 & 686.9 & 757.6 & 649.1 & $694.5 \pm 36.6$ \\
\hline
\end{tabular}

BMI: body mass index. ${ }^{a} \mathrm{BW}$ changed significantly during the $11 \mathrm{~d}$ of this study $(p<0.01)$.

The running distance of the subjects during a previous month is shown as a reference. The running distance of the subjects during this study was not surveyed.

\begin{tabular}{|l|c|c|c|c|c|c|c|c|c|c|c|}
\hline Day & 1 & 2 & 3 & 4 & 5 & 6 & 7 & 8 & 9 & 10 & 11 \\
\hline Anthropometry & $\bigcirc$ & & & & & & & & & & $\bigcirc$ \\
\hline Exercise test & $\bigcirc$ & & $\bigcirc$ & & & & & & & & \\
\hline BMR measurement & $\bigcirc$ & & $\bigcirc$ & & & & & & & & \\
\hline Dietary records & $\bigcirc$ & $\bigcirc$ & $\bigcirc$ & $\bigcirc$ & $\bigcirc$ & $\bigcirc$ & $\bigcirc$ & $\bigcirc$ & $\bigcirc$ & $\bigcirc$ & $\bigcirc$ \\
\hline HR monitoring & $\bigcirc$ & & & & & $\bigcirc$ & & $\bigcirc$ & & $\bigcirc$ & \\
\hline
\end{tabular}

Fig. 1. The study protocol. Various measurements and the days on which they were recorded are shown. BW and body fat (\%) were measured on day 1 . The calibration procedure (exercise test and BMR measurement) was carried out on days 1 and 3. The daily dietary intake was measured by weighing the meals on each of the $11 \mathrm{~d}$. The minute-by-minute HR monitoring for $24 \mathrm{~h}$ was carried out four times on days $1,6,8$, and 10 . 
time was usually scheduled for twice a day, between 6:00-7:20 AM and 3:50-7:00 PM, but each of the subjects set their own individually different training routines.

Anthropometry and body composition. BW and body fat $(\%)$ were measured in light underwear without shoes using an electronic scale with a bioelectrical impedance function (TBF-102, Tanita, Tokyo, Japan). Body mass index (BMI) was calculated by dividing BW in kilograms by the square of height in meters $\left(\mathrm{kg} / \mathrm{m}^{2}\right)$.

Regression analysis of individual HR-EE relationship and $24 \mathrm{~h} \mathrm{HR}$ monitoring. Each subject underwent a calibration experiment to determine his own HR and EE relationship. This calibration procedure was carried out in the daytime, $3 \mathrm{~h}$ after breakfast. To determine the individual HR-EE relationship, different activities were performed such as lying supine and cycle ergometer exercise (Aerobike, Combi Wellness Co. Ltd., Tokyo, Japan). The ergometer exercise was performed at a speed of $50 \mathrm{rpm}$ with light $(50 \mathrm{~W})$, middle $(100 \mathrm{~W})$, heavy $(150 \mathrm{~W})$, or very heavy $(200 \mathrm{~W})$ loading. The exercising time was $5 \mathrm{~min}$, and respiratory air was collected using a Douglas bag for the last 1 min while HR was being recorded with a telemetric HR monitor (Polar Vantage XL, Polar Electro, Finland). The expired air of each subject was analyzed by a respiratory mass spectrometer (WT10, Shinagawa Co. Ltd., Tokyo, Japan). The oxygen concentration was determined using a magnetic formula analyzer (PMA-200, Horiba, Ltd., Kyoto, Japan), and carbon dioxide concentration by a non-diffusion type infrared analysis meter (VIA-210, Horiba, Ltd.). EE was computed from oxygen consumption and carbon dioxide production according to Weir's equation. HR and EE were plotted in pairs with individual data, and an exponential curve with the best fit for each dataset was drawn for each subject (Fig. 2). The curvilinear relationship between HR and EE was modeled on a log-linear function for the reason explained in the introductory section $(13,24-27)$. After the individual HR-EE relation was determined, EE per minute was derived by using the individual HR-EE calibration formula. It was done for each corresponding HR datum recorded over the 24-h monitoring period. TEE was computed by summing up every EE per minute over the entire sampling period. EE for sleep, exercise (training) and inactivity (other daily habitual activities) was also calculated in a similar way.

The minute-by-minute HR monitoring for $24 \mathrm{~h}$ was carried out four times on days 1, 6, 8, and 10 for each subject in this study. Figure 3 shows how the mean HR of the group varied during a typical day. At 6:50 PM, they set a HR monitor after taking a shower, and at 11:00 PM they went to bed. They got up at 5:50 AM and then were engaged in the first training for $1.5 \mathrm{~h}$. Thereafter, they spent their normal daily lives and began the second training from 4:00 to 6:50 PM.

Energy intake. The daily food intake of the subjects was surveyed in advance, and the energy and nutrient composition of the meals was standardized based on the study by Hawley et al. The total energy was set at 3,700

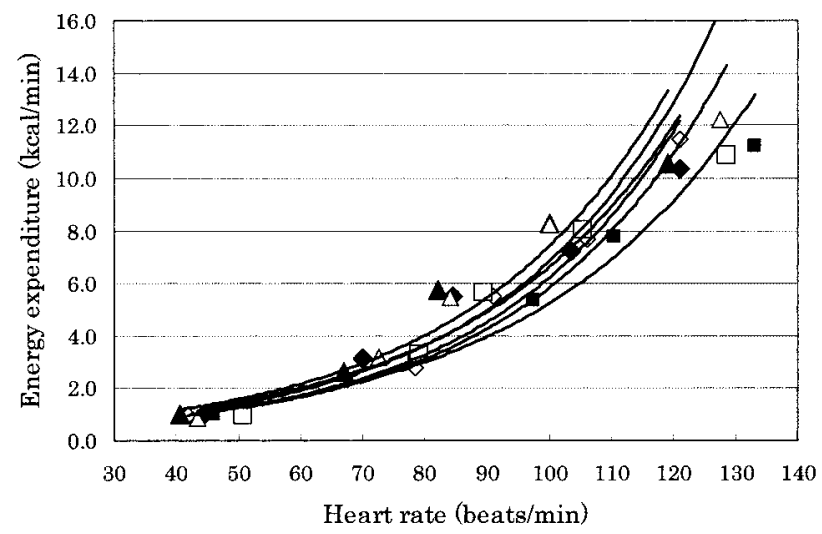

Fig. 2. HR-EE regression curves of test subjects. Runner A $(\diamond): y=0.337 e^{0.030 x}, R^{2}=0.944$. Runner $\mathrm{B}(\diamond)$ : $y=0.254 e^{0.032 x}, \quad R^{2}=0.988$. Runner C $(\mathbf{\Delta}): \quad y=$ $0.343 e^{0.031 x}, R^{2}=0.951$. Runner D $(\triangle): y=0.286 e^{0.032 x}$, $R^{2}=0.933$. Runner E (ם): $y=0.320 e^{0.028 x}, R^{2}=0.981$. Runner F $(\square): y=0.252 e^{0.031 x}, R^{2}=0.931$.

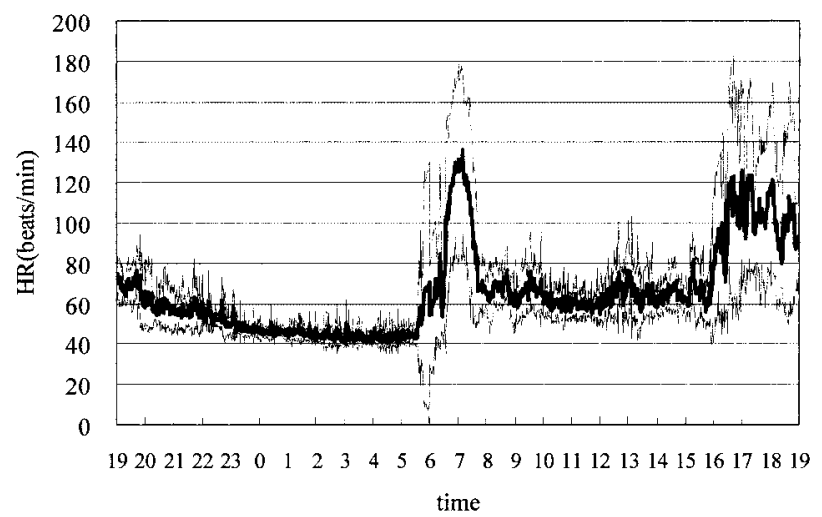

Fig. 3. Mean changes in the 24-h heart rate of test subjects. Bold line: mean, Fine line: SD. In a 24-h cycle, the subjects put on the HR monitor at 6:50 PM, went to bed at 11:00 PM, got up at 5:50 PM and engaged in training for $1.5 \mathrm{~h}$, started second training at 4:00 PM, and completed monitoring at 6:50 PM.

$\mathrm{kcal} / \mathrm{d}$, with protein at $15 \%$, fat at 25 to $30 \%$, and carbohydrates at 55 to $60 \%$, of the total energy (2). For each subject, the daily dietary intake was measured by weighing the meals on each of the $11 \mathrm{~d}$ of this study, and the intake was calculated using nutrition calculation software, Excel Eiyoukun (Kenpakusha, Tokyo, Japan). Subjects were forbidden from eating snacks and drinking juices or alcohol to strictly control the energy intake.

Statistical analysis. All the data are expressed as mean and standard deviation (SD). The statistical evaluations were carried out with SPSS for Windows software (version $11.5 \mathrm{~J}$; SPSS Inc., Tokyo, Japan). When the probabilities were less than 0.05 , the statistical test was regarded as significant.

\section{RESULTS}

\section{Anthropometric analysis}

The physical characteristics of the six subjects are shown in Table 1. Their BMIs, 18.3-20.0, were in a normal range. Their body fat ratios varied from 9.4 to 
Table 2. Heart rate and time for sleep, inactivity and exercise.

\begin{tabular}{|c|c|c|c|c|c|c|c|c|c|}
\hline Subject & & & A & B & C & $\mathrm{D}$ & $\mathrm{E}$ & $\mathrm{F}$ & Mean \pm SD \\
\hline \multirow[t]{3}{*}{$\begin{array}{l}\text { Heart rate } \\
\text { (beats/min) }\end{array}$} & Sleep & $\begin{array}{l}\text { mean } \\
\text { range }\end{array}$ & $\begin{array}{l}44.4 \pm 1.2 \\
(43-45)\end{array}$ & $\begin{array}{l}43.0 \pm 0.8 \\
(43-45)\end{array}$ & $\begin{array}{l}41.9 \pm 2.3 \\
(40-45)\end{array}$ & $\begin{array}{l}40.8 \pm 1.1 \\
(39-42)\end{array}$ & $\begin{array}{l}46.8 \pm 0.2 \\
(46-47)\end{array}$ & $\begin{array}{l}45.5 \pm 0.7 \\
(45-46)\end{array}$ & $43.9 \pm 2.2$ \\
\hline & Inactivity & $\begin{array}{l}\text { mean } \\
\text { range }\end{array}$ & $\begin{array}{l}60.7 \pm 3.6 \\
(56-64)\end{array}$ & $\begin{array}{l}60.4 \pm 3.0 \\
(57-64)\end{array}$ & $\begin{array}{l}52.2 \pm 3.4 \\
(49-57)\end{array}$ & $\begin{array}{l}61.3 \pm 3.6 \\
(57-65)\end{array}$ & $\begin{array}{l}63.7 \pm 2.5 \\
(62-67)\end{array}$ & $\begin{array}{l}60.1 \pm 2.7 \\
(57-63)\end{array}$ & $59.7 \pm 3.9$ \\
\hline & Exercise & $\begin{array}{l}\text { mean } \\
\text { range }\end{array}$ & $\begin{array}{r}135.0 \pm 3.9 \\
(130-139)\end{array}$ & $\begin{array}{l}121.4 \pm 1.2 \\
(120-123)\end{array}$ & $\begin{array}{r}120.9 \pm 4.9 \\
(116-128)\end{array}$ & $\begin{array}{l}121.0 \pm 15.3 \\
(100-134)\end{array}$ & $\begin{array}{r}131.2 \pm 9.2 \\
(122-143)\end{array}$ & $\begin{array}{l}128.9 \pm 13.3 \\
(120-143)\end{array}$ & $126.6 \pm 6.1$ \\
\hline \multirow[t]{3}{*}{$\begin{array}{l}\text { Time length } \\
\text { (min) }\end{array}$} & Sleep & $\begin{array}{l}\text { mean } \\
\text { range }\end{array}$ & $\begin{array}{c}480 \pm 49 \\
(421-540)\end{array}$ & $\begin{array}{c}458 \pm 29 \\
(420-480)\end{array}$ & $\begin{array}{l}445 \pm 106 \\
(361-600)\end{array}$ & $\begin{array}{c}476 \pm 40 \\
(416-496)\end{array}$ & $\begin{array}{c}474 \pm 38 \\
(421-511)\end{array}$ & $\begin{array}{c}466 \pm 14 \\
(405-511)\end{array}$ & $466 \pm 13$ \\
\hline & Inactivity & $\begin{array}{l}\text { mean } \\
\text { range }\end{array}$ & $\begin{array}{c}836 \pm 36 \\
(794-875)\end{array}$ & $\begin{array}{c}857 \pm 37 \\
(833-912)\end{array}$ & $\begin{array}{c}896 \pm 145 \\
(683-1,000)\end{array}$ & $\begin{array}{l}879 \pm 18 \\
(860-903)\end{array}$ & $\begin{array}{l}863 \pm 27 \\
(829-895)\end{array}$ & $\begin{array}{c}882 \pm 31 \\
(839-913)\end{array}$ & $869 \pm 21$ \\
\hline & Exercise & $\begin{array}{l}\text { mean } \\
\text { range }\end{array}$ & $\begin{array}{l}124 \pm 52 \\
(85-200)\end{array}$ & $\begin{array}{l}126 \pm 40 \\
(78-175)\end{array}$ & $\begin{array}{c}99 \pm 41 \\
(64-157)\end{array}$ & $\begin{array}{l}85 \pm 25 \\
(64-121)\end{array}$ & $\begin{array}{c}104 \pm 40 \\
(64-160)\end{array}$ & $\begin{array}{l}92 \pm 28 \\
(67-122)\end{array}$ & $105 \pm 17$ \\
\hline
\end{tabular}

Individual data was obtained on $4 \mathrm{~d}$ (days $1,6,8,10$ ) during the 11-d study.

Sleep: lay in bed, Inactivity: other daily habitual activities, Exercise: engaged in training.

Mean and range: data for $4 \mathrm{~d}$. There was no significant individual difference among all the subjects.

Table 3. TEE, EE of sleep, inactivity and exercise, and energy intake.

\begin{tabular}{|c|c|c|c|c|c|c|c|c|}
\hline Subject & & A & B & $\mathrm{C}$ & D & $\mathrm{E}$ & $\mathrm{F}$ & Mean \pm SD \\
\hline BMR & $(\mathrm{kcal} / \mathrm{d})$ & 1,527 & 1,677 & 1,614 & 1,604 & 1,507 & 1,555 & $1,581 \pm 63$ \\
\hline TEE & $(\mathrm{kcal} / \mathrm{d})$ & $5,960 \pm 1,496$ & $4,565 \pm 983$ & $4,113 \pm 761$ & $4,369 \pm 1,674$ & $3,993 \pm 1,052$ & $4,082 \pm 1,199$ & $4,514 \pm 739$ \\
\hline Sleep-EE & $\begin{array}{l}(\mathrm{kcal} / \mathrm{d}) \\
(\%)^{\mathrm{a}}\end{array}$ & $\begin{array}{c}601 \pm 61 \\
(10.1)\end{array}$ & $\begin{array}{c}484 \pm 25 \\
(10.6)\end{array}$ & $\begin{array}{c}567 \pm 181 \\
(13.8)\end{array}$ & $\begin{array}{c}503 \pm 40 \\
(11.5)\end{array}$ & $\begin{array}{c}560 \pm 49 \\
(14.0)\end{array}$ & $\begin{array}{c}502 \pm 50 \\
(12.3)\end{array}$ & $\begin{array}{c}536 \pm 46 \\
(12.0 \pm 1.6)\end{array}$ \\
\hline Inactivity-EE & $\begin{array}{l}(\mathrm{kcal} / \mathrm{d}) \\
(\%)^{\mathrm{a}}\end{array}$ & $\begin{array}{c}1,853 \pm 248 \\
(31.1)\end{array}$ & $\begin{array}{c}1,642 \pm 181 \\
(36.0)\end{array}$ & $\begin{array}{c}1,600 \pm 192 \\
(38.9)\end{array}$ & $\begin{array}{c}1,936 \pm 298 \\
(44.3)\end{array}$ & $\begin{array}{c}1,725 \pm 131 \\
(43.2)\end{array}$ & $\begin{array}{c}1,578 \pm 65 \\
(38.7)\end{array}$ & $\begin{array}{r}1,722 \pm 145 \\
(38.7 \pm 4.8)\end{array}$ \\
\hline Exercise-EE & $\begin{array}{l}(\mathrm{kcal} / \mathrm{d}) \\
(\%)^{\mathrm{a}}\end{array}$ & $\begin{array}{c}3,507 \pm 1,511 \\
(58.8)\end{array}$ & $\begin{array}{c}2,439 \pm 961 \\
(53.4)\end{array}$ & $\begin{array}{c}1,946 \pm 801 \\
(47.3)\end{array}$ & $\begin{array}{c}1,930 \pm 1,505 \\
(44.2)\end{array}$ & $\begin{array}{c}1,708 \pm 984 \\
(42.8)\end{array}$ & $\begin{array}{c}2,003 \pm 1,266 \\
(49.0)\end{array}$ & $\begin{array}{r}2,255 \pm 658 \\
(49.3 \pm 6.0)\end{array}$ \\
\hline Energy intake & $(\mathrm{kcal} / \mathrm{d})$ & $3,728 \pm 233$ & $3,709 \pm 308$ & $3,793 \pm 253$ & $3,874 \pm 391$ & $3,909 \pm 304$ & $3,688 \pm 389$ & $3,784 \pm 91$ \\
\hline Energy balance & $(\mathrm{kcal} / \mathrm{d})$ & $-2,232$ & -835 & -320 & -495 & -84 & -394 & $-730 \pm 777$ \\
\hline
\end{tabular}

TEE: total daily energy expenditure. EE: energy expenditure. Individual data of the above EEs are the mean of four measurement days, and those of energy intake are the means of $11 \mathrm{~d}$. Energy balance was calculated from TEE and energy intake.

aPercentage of TEE.

Sleep: lay in bed, Inactivity: other daily habitual activities, Exercise: Engaged for training.

15.9\%. Small but statistically significant changes in BW, $-0.8 \pm 1.0 \mathrm{~kg}$, were observed during the study period of $11 \mathrm{~d}$ (Table $1, p<0.01$ ).

2. Individual HR-EE regression

Figure 2 shows six individual HR-EE curves. All the regression formulas deduced from the HR-EE data were satisfactory as judged from the high coefficients of determination $\left(R^{2}=0.931-0.988\right)$.

3. HR and time length of sleep, inactivity and exercise

The means of HR and length of time for the three component activities are shown in Table 2 and Fig. 3. The variation range of individual HR for sleep, inactivity and exercise was 40.8-46.8 (mean: 43.9 \pm 2.2 )

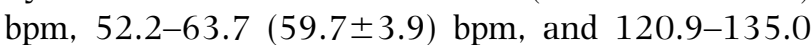
(126.6 \pm 6.1$) \mathrm{bpm}$, respectively. The mean HRs for inactivity and exercise were 1.4 times and 2.9 times of the mean sleep HR. The time for the three activities varied

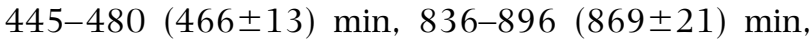
and 85-126 (105 \pm 17$) \mathrm{min}$, respectively. The ratio for $24 \mathrm{~h}$ of the three components was $32.4 \%$ for sleep, $60.3 \%$ for inactivity and, $7.3 \%$ for exercise. One-way ANOVA showed no difference between individuals in any of the above data.

4. TEE, its partition into three components and EI

The TEE of the six subjects varied from 3,993 to 5,960 (mean: 4,514 \pm 739 ) kcal while the means of sleep EE, inactivity EE and exercise EE fluctuated in the range of 484-601 $(536 \pm 46) \mathrm{kcal}, \quad 1,600-1,853$ $(1,722 \pm 145) \mathrm{kcal}$ and $1,708-3,507 \quad(2,255 \pm 658)$ kcal, respectively (Table 3 ). No difference was observed in TEE between individuals according to one-way ANOVA. The ratio of each component to TEE was 10.1$14.0 \%$ for sleep EE, $31.1-44.3 \%$ for inactivity EE and $42.8-58.8 \%$ for exercise EE.

The individual EIs and mean EI $(3,784 \pm 91 \mathrm{kcal})$ were less than the corresponding TEE. These negative balances in energy resulted in a decrease in BW of all the subjects except for runner $\mathrm{F}$ at the end of the study, leading to a significant decrease in the average BW (Table 1).

5. Correlation between TEE and each component

The Pearson correlation coefficients between TEE and each EE of sleep, inactivity, and exercise are presented in Table 4. The coefficient was positively significant 
Table 4. Pearson correlation coefficients between TEE and EE of either sleep, inactivity or exercise.

\begin{tabular}{llrrrrrrr}
\hline \multicolumn{1}{c}{ Subject } & & A & B & C & D & E & F & 6 subjects \\
\hline Correlation coefficient & Sleep & -0.571 & -0.455 & 0.609 & -0.986 & -0.842 & -0.778 & -0.025 \\
& Inactivity & 0.145 & 0.260 & -0.738 & 0.746 & 0.851 & -0.375 & 0.365 \\
& Exercise & 0.990 & 0.985 & 0.989 & 0.991 & 0.998 & 0.997 & 0.987 \\
$p$-value & & & & & & & & \\
& Sleep & 0.215 & 0.273 & 0.195 & 0.007 & 0.079 & 0.111 & 0.908 \\
& Inactivity & 0.428 & 0.370 & 0.131 & 0.127 & 0.075 & 0.312 & 0.079 \\
& Exercise & 0.005 & 0.007 & 0.005 & 0.005 & 0.001 & 0.001 & 0.000 \\
\hline
\end{tabular}

between TEE and exercise EE for every subject (mean: $r=0.992 \pm 0.005, p=0.004 \pm 0.002$ ). The correlation between TEE and sleep EE was negative in general, but significant only for runner D.

\section{DISCUSSION}

Information on TEE, resting energy expenditure (REE), and EE of physical activities like exercise is important to provide athletes with adequate nutritional support. It is not just the energy requirement, but consumption of the major nutrient groups (i.e., protein, fat and carbohydrates) is all closely linked to TEE. Therefore, it is necessary to measure TEE and its components (EE for exercise and other activities) as precisely as possible in various athletes (29). Once TEE or energy requirement is accurately determined, appropriate dietary recommendations for individual athletes can be made to ensure a proper nutritional balance $(29,30)$. Therefore, different trials have been conducted in this field of study in an attempt to achieve an optimal nutritional and energy balance for athletes (30).

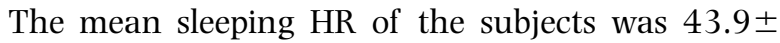
$2.2 \mathrm{bpm}$ (Table 2), lower than that of untrained individuals or trained resistance individuals, and similar to those of trained endurance men (8). There is abundant evidence that trained individuals have higher HR variability, due to profound bradycardia, than untrained individuals (18). The athlete's heart often features a physiological adaptation depending on the intensity and duration of the training (31). Long-term agonistic activities can produce a cardiac enlargement and hypertrophy with some modifications to wall thickness, left ventricular cavity dimension and cardiac mass (31).

EEs are usually calculated or measured using the DLW method, HR method, and other simpler methods (32). The DLW method is the most accurate of all, but is inconvenient for monitoring EEs of shorter duration and collecting a sufficient amount of data. With regards to the DLW method, Rafamantanantsoa et al. suggested that the accelerometer is superior to HR monitor in estimating the TEE of older individuals (32). But Crouter et al. pointed out that the use of motion sensors such as electronic pedometers or accelerometers is limited to measuring ambulatory activities. Further, they reported the limitations and ineffectiveness of these devices for predicting the energy costs of such activities as walking or running up an incline (16). They also indicated that uniaxial motion sensors cannot accu- rately detect increases in $\mathrm{EE}$ at running speeds over $9 \mathrm{~km} / \mathrm{h}$ (16). Furthermore, Thompson et al. reported that the HR method provides an accurate estimate of $\mathrm{EE}$, whereas the pedometer does not (33). Therefore, it is inappropriate to apply these methods to measuring EEs in active athletes.

On the other hand, portable HR monitors have been widely used to estimate the exercise intensity in sports training and competition (34). This is a simple and relatively reliable method, often comparable to DLW, based on the regression analysis of $\mathrm{HR}$ and $\mathrm{EE}$, and thereby particularly suitable for measuring the EE in athletes. The accuracy of the HR method largely depends on the regression analysis. In each of the present participants, a strong correlation was observed between HR and EE, giving a well-fitted regression formula (Fig. 2). Taking the high coefficients of determination into consideration, the results in this study were considered very reliable. The slope of the HR-EE curves of the subjects in the present study is clearly steeper than that of non-trained individuals previously reported by other researchers $(13,14,16,20,27)$. It indicates that the steepness of the slope is likely to predict or estimate an individual's fitness level. Despite frequent use of the HR method, however, care should be taken in estimating the EE in athletes. Factors such as mental stress, hydration level, modes of exercise, gender, training status, and environmental factors like temperature and humidity can all unduly influence experimental results by causing fluctuation in the EE at the same or similar HR (18). It must also be considered that time-lag often occurs in HR response to quick changes in training intensity, possibly introducing small errors in the HR method (18). In our 24-h study, strict control of the above factors was not possible, hence further improvement of experimental conditions is preferred as suggested by Garet et al. (35). However, mental stress induced when using a HR monitor is considered small. The subjects are accustomed to using HR monitors as a tool for estimating their own training intensity. Our 24-h monitoring also covered illeffects due to time lag, which possibly occur in shortterm monitoring. In addition, the present subjects were not exposed to extreme conditions such as severe hydration, temperature, and humidity.

In the present study, the mean TEE and EI of the six endurance runners were $4,514 \pm 739 \mathrm{kcal} / \mathrm{d}$ and $3,784 \pm 91 \mathrm{kcal} / \mathrm{d}$, respectively (Table 3 ). Parts of the training menu were chosen by each subject, as a result 
of which there are differences in the energy expenditure amongst the subjects. Suzuki et al. examined the accuracy of the Calorie Counter method (CC method) to assess daily EE in male athletes (karate, soccer, basketball, tennis, and baseball players) and male/female nonathletes, and found that the male athlete's average TEE was $9,630 \pm 1,250 \mathrm{~kJ} / \mathrm{d}(2,768 \pm 299 \mathrm{kcal} / \mathrm{d})(3)$. Ebine et al. measured the TEE of elite synchronized swimmers and of professional soccer players using the DLW method, and found that the mean TEE and EI of the latter were $3,532 \pm 408 \mathrm{kcal} / \mathrm{d}(4,5)$. The TEE observed from our test subjects was clearly higher than the above. However, the mean TEE of endurance athletes reported by Grund et al. $(4,493 \pm 1,888 \mathrm{kcal} / \mathrm{d}, 1,840-$ $7,504 \mathrm{kcal} / \mathrm{d}$ ), was similar to that observed in the present study $(8)$. Their procedure for TEE measurement was similar to ours, which is the combination of indirect calorimetry and individually calibrated 24-h HR monitoring. These results indicate that the daily energy requirement of the subjects was 4,000$5,000 \mathrm{kcal}$, which is higher than that of other athletes; this is a known characteristic of long-distance runners.

During this study, five of the six subjects, except runner F, exhibited a significant loss of BW (Table 2). Kien and Ugrasbul (36) reported that changes in BW of up to $0.3 \mathrm{~kg}$ are expected due to the deviation in energy balance of $\sim 100-200 \mathrm{kcal} / \mathrm{d}$, lasting over $3 \mathrm{~d}$. This takes into account extraneous factors such as exercise habits, hydration status, ambient temperature and bowel habits. Potteiger et al. (37) also reported a gradual decrease in BW brought about by a negative calorie balance. However, Kien and Ugrasbul, and Potteiger et al. suggested the possibility that $\mathrm{EE}$ in runners may become more efficient during running because of extensive training and metabolic adaptation $(36,37)$, which might obscure the BW change to a lesser extent. A decline in BW itself certainly occurred in this study and cannot be overlooked for managing the energy balance of athletes. Ebine et al. reported that the EI of soccer players was 3,113 $\pm 581 \mathrm{kcal} / \mathrm{d}$ (5). Sugiura et al.

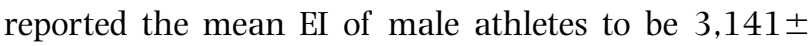
$592 \mathrm{kcal} / \mathrm{d}$, and claimed the necessity of nutritional counseling to optimize energy and nutrient intake during training (12). These studies, as well as our data, indicate that athletes need an EI of at least 3,000$4,500 \mathrm{kcal}$, in some instances up to $5,000 \mathrm{kcal}$, and more energy must be supplied when they are engaged in vigorous training.

The exercise intensity estimated from HR as a measure of activity was different from subject to subject in this study, which accounts for the rather large variation in the ratios of exercise EE to TEE, 42.8 to $58.8 \%$ (mean: $49.3 \%$ ). The ratios themselves, however, were noticeably high, constituting around 50\% of TEE, and significant correlations between TEE and exercise EE were found in all the subjects (Table 4). Sometimes volume estimates from literature are used in determining athlete energy balance, based on the length of training time or the apparent exercise intensities. In view of the above results, the actual readings from exercise EE should be used for any nutrition and/or energy management provided for endurance athletes. There is a general tendency in sports nutrition to pay attention only to TEE or REE in managing energy balance. However, it is important to take a holistic view of the management of EE in daily life and divide TEE into various activities within the day. Especially, the volume and intensity of the training exercises, which have a greater effect on TEE, should be emphasized.

As this study was focused only on 24-h heart rate monitoring, the subjects were allowed to lead a normal life as far as possible. Therefore, their daily physical activities were not individually monitored. However, such a study is important and needs to be carried out in the future. A reliable monitoring protocol is not available and difficult to develop, especially, for investigating the direct relationship between the three meals and various physical activities. Effects of meals have been under investigation by some researchers who recommend the intake of nutrient supplements and/or foods like banana shortly after exercise. But these studies are still too premature to draw general conclusions. The present study clearly addresses the holistic approach to energy balance, and at the same time, draws attention to the problems involved in allocating EE. It is difficult to allocate specific EE to activities in the daily lives of athletes, such as those described in this report.

This study offers the first step towards the goal of estimating the $\mathrm{EE}$ in athletes by collecting and presenting data from detailed analyses of daily activities, in addition to athletic training. Further, it highlights the risk associated with negative energy balance in athletes by comparing TEE with EI; which points to the importance of nutritional care for maintaining proper energy balance with desirable nutritional status in athletes during practice. Nutritional management so far has focused on body maintenance or fitness levels based on body weight, composition, and blood index. However, energy intake has a positive effect on the improvement of athletic performance. Although this study is aimed at estimating the TEE of Japanese athletes, many other issues remain unexamined. For example, the importance of nutrient supplements for improving performance, countering the decline in energy storage due to longterm training, and metabolic responses to body changes during training; all of which are issues to be regarded.

\section{Acknowledgments}

The work described in this publication was supported by Grants-in-Aid for Scientific Research and Knowledge Cluster Initiative from the Ministry of Education, Culture, Sports, Science and Technology of Japan (to KM, and ET), and from the 21st Century COE Program, Human Nutritional Science on Stress Control Tokushima, Japan.

\section{REFFERENCES}

1) Ekelund U, Yngve A, Westerterp K, Sjostrom M. 2002. Energy expenditure assessed by heart rate and doubly labeled water in young athletes. Med Sci Sports Exerc 34: 
1360-1366.

2) Hawley JA, Dennis SC, Lindsay FH, Noakes TD. 1995. Nutritional practices of athletes: Are they sub-optimal? J Sports Sci 13(Spec): S75-S81.

3) Suzuki I, Kawakami N, Shimizu H. 1997. Accuracy of calorie counter method to assess daily energy expenditure and physical activities in athletes and nonathletes. J Sports Med Phys Fitness 37: 131-136.

4) Ebine N, Fen JY, Homma M, Saitoh S, Jones P. 2000. Total energy expenditure of elite synchronized swimmers measured by the doubly labeled water method. Eur J Appl Physiol. 83: 1-6.

5) Ebine N, Rafamantanantsoa HH, Nayuki Y, Yamanaka K, Tashima K, Ono T, Saitoh S, Jones P. 2002. Measurement of total energy expenditure by the doubly labeled water method in professional soccer players. J Sports Sci 20: 391-397.

6) Slawinski JS, Billat VL. 2004. Difference in mechanical and energy cost between highly, well, and nontrained runners. Med Sci Sports Exerc 36: 1440-1446.

7) Bergman BC, Brooks GA. 1999. Respiratory gasexchange ratios during graded exercise in fed and fasted trained and untrained men. J Appl Physiol 86: 479487.

8) Grund A, Krause H, Kraus M, Siewer M, Rieckert H, Muller MJ. 2001. Association between different attributes of physical activity and fat mass in untrained, endurance- and resistance- trained men. Eur J Appl Physiol 84:310-320.

9) Spurr GB, Prentice AM, Murgatroyd PR, Goldberg GR, Reina JC, Christman NT. 1988. Energy expenditure from minute-by-minute heart-rate recording: comparison with indirect calorimetry. Am J Clin Nutr 48: 552559.

10) Onywera VO, Kiplamai FK, Boit MK, Pitsiladis YP. 2004. Food and macronutrient intake of elite Kenyan distance runners. Int J Sport Nutr Exerc Metab 14 : 709-719.

11) Thompson JL, Manore MM, Skinner JS, Ravussin E, Spraul M. 1995. Daily energy expenditure in male endurance athletes with differing energy intakes. Med Sci Sports Exerc 27 : 347-354.

12) Sugiura K, Suzuki I, Kobayashi K. 1999. Nutritional intake of elite Japanese track-and-field athletes. Int $J$ Sport Nutr 9: 202-212.

13) Kashiwazaki H. 1999. Heart rate monitoring as a field method for estimating energy expenditure as evaluated by the doubly labeled water method. J Nutr Sci Vitaminol 45: 79-94.

14) Crouter SE, Albright C, Bassett DR Jr. 2004. Accuracy of polar $\mathrm{S} 410$ heart rate monitor to estimate energy cost of exercise. Med Sci Sports Exerc 36: 1433-1439.

15) Achten J, Juelendrup AE. 2003. Heart rate monitoring. Applications and limitations. Sports Med 33: 517-538.

16) Booyens J, Hervey GR. 1960. The pulse rate as a means of measuring metabolic rate in man. Can J Biochem Physiol 38: 1301-1309.

17) Miller SL, Wolfe RR. 1999. Physical exercise as a modulator of adaptation to low and high carbohydrate and low and high fat intakes. Eur J Clin Nutr 53(Suppl). : s112-s119.

18) Livingstone MB, Prentice AM, Coward WA, Ceesay SM, Strain JJ, McKenna PG, Nevin GB, Barker ME, Hickey RJ. 1990. Simultaneous measurement of free- living energy expenditure by the doubly labeled water method and heart- rate monitoring. Am J Clin Nutr 53: 59-65.
19) Dauncey MJ, James WP. 1979. Assessment of the heartrate method for determining energy expenditure in man, using a whole-body calorimeter. Br J Nutr 42: 113.

20) Li R, Deurenberg P, Hautvast JG. 1993. A critical evaluation of heart rate monitoring to assess energy expenditure in individuals. Am J Clin Nutr 58: 602-607.

21) Ceesay SM, Prentice AM, Day KC, Murgatroyed PR, Goldberg GR, Scott W, Spurr GB. 1989. The use of heart rate monitoring in the estimation of energy expenditure: a validation study using indirect whole- body calorimetry. Br J Nutr 61: 175-186.

22) Leonard WR, Katzmarzyk PT, Stephen MA, Ross AG. 1995. Comparison of the heart rate-monitoring and factorial methods: assessment of energy expenditure in highland and coastal Ecuadoreans. Am J Clin Nutr 61: 1146-1152.

23) McCrory MA, Mole PA, Nommsen Rivers LA, Dewey Kg. 1997. Between-day and within-day variability in the relation between heart rate and oxygen consumption: effect on the estimation of energy expenditure by heartrate monitoring. Am J Clin Nutr 66: 18-25.

24) Acheson KJ, Campbell IT, Edholm OG, Miller DS, Stock MJ. 1980. The measurement of daily energy expenditure - an evaluation of some techniques. Am J Clin Nutr 33: $1155-1164$.

25) Kashiwazaki H, Inaoka T, Suzuki T, Tamada T. 1985. Daily energy expenditure of middle-aged Japanese housewives measured by 24-hour heart rate and diary. Nutr Res 5: 453-463.

26) Schluz S, Westerterp KR, Bruck K. 1989. Comparison of energy expenditure by the doubly labeled water technique with energy intake, heart rate, and activity recording in man. Am J Clin Nutr 49: 1146-1154.

27) Della Bianca P, Jequer E, Schutz Y. 1994. Lack of metabolic and behavioral adaptation in rural Gambian men with low body mass index. Am J Clin Nutr 60: 37-42.

28) Murayama N, Ohtsuka R. 1999. Seasonal fluctuation in energy balance among farmers in Northeast Thailand: The lack of response of energy intake to the energy expenditure. Eur J Clin Nutr 53: 39-49.

29) De Lorenzo A, Bertini I, Candeloro N, Piccinelli R, Innocente I, Brancati A. 1999. A new predictive equation to calculate resting metabolic rate in athletes. Sports Med Phys Fitness 39: 213-219.

30) Thompson J, Manore MM. 1996. Predicted and measured resting metabolic rate of male and female endurance athletes. J Am Diet Assoc 96: 30-34.

31) Palazzuoli A, Puccetti L, Pastorelli M, Pasqui A, Auteri A, Bruni F. 2002. Transimitral and pulmonary venous flow study in elite male runners and young adults. Int $J$ Cardiol 84: 47-51.

32) Rafamantanantsoa HH, Ebine N, Yoshioka M, Higuchi H, Yoshitake Y, Tanaka H, Saitoh S, Jones PJ. 2002. Validation of three alternative methods to measure total energy expenditure against the doubly labeled water method for older Japanese men. J Nutr Sci Vitaminol 48 : 517-523.

33) Thompson D, Batterham AM, Bock S, Robson C, Stokes K. 2006. Assessment of low-to-moderate intensity physical activity thermogenesis in young adults using synchronized heart rate and accelerometry with branchedequation modeling. J Nutr 136: 1037-1042.

34) Esteve-Lanao J, Juan A, Earnest C, Foster C, Lucia A. 2005. How do endurance runners actually train? Rela- 
tionship with competition performance. Med Sci Sports Exerc 37: 496-504.

35) Garet M, Boudet G, Montaurier C, Vermorel M, Coudert J, Chamoux A. 2005. Estimating relative physical workload using heart rate monitoring: a validation by wholebody indirect calorimetry. Eur J Appl Physiol 94: 46-53.

36) Kien CL, Ugrasbul F. 2004. Prediction of daily energy expenditure during a feeding trial using measurements of resting energy expenditure, fat-free mass, or HarrisBenedict equations. Am J Clin Nutr 80: 876-880.

37) Potteiger J, Welch J, Byrne J. 1993. From parturition to marathon: a 16-wk study of an elite runner. Med Sci Sports Exerc 25: 673-677. 